\title{
The South Ion-Absorbed Rare Earth Mine Area Remote Sensing Monitoring in South of Jiangxi Province, China
}

\author{
Yan Peng, Guojin He, and Zhaoming Zhang
}

\begin{abstract}
Three kinds of the south ion-absorbed rare earth mine (REM) which are Lingbei REM region with light rare earth element (REE), Zudong REM region with high REE and Longshe REM region with middle high REE respectively were chosen as study areas in this paper. In order to make land cover maps and therefore monitor the changes of the exploitation of study areas during 2000-2010, object-oriented classification were conducted using SPOT1/2/5, and ALOS satellite imageries. A retrospective approach was also used to reduce the false change information, and thus to extract the change information of rare earth mining area efficiently. It is found that the three south ion-absorbed REM areas were scattered in study areas, and the exploitation areas of Lingbei and Zudong REM tends to increase from 2000 to 2010 resulting in forest reduced mainly, while the exploitation areas of Longshe REM decreased from 2000 to 2010 resulting in farmland increased owing to the fact that the mining area was forced to abandon in 2003 and began to carry out reclamation after then. In order to analyze the reclaimed vegetation condition, tasseled cap transformation was employed using Landsat5-7 imagery. The analysis shows that the green vegetation increases from 2000 to 2010. It indicated that the region achieved remarkable effects in reclamations, and the success of reclamation practices could provide guidance for the reclamation of other south ion-absorbed REM region.
\end{abstract}

Index Terms-Ion-absorbed rare earth mining area, object-oriented classification, backtracking, reclamation, Tasseled Cap transformation.

\section{INTRODUCTION}

Rare Earth Mine has been widely used in many fields, such as machine manufacturing, petrochemical industry, spaceflight and aero aviation and so on. With the demand increased for the rare earth resource, disordered mining phenomenon has become seriously. However, the improper mining way will cause many environmental problems, such as water and soil pollution, soil erosion and so on. These problems have affected human's life, also restricted regional sustainable development. So it is necessary to monitor the rare earth mine exploitation. The conventional field and laboratory measurements are time-consuming, inefficient and long cycle for a large-scale surface mine area. With the development of remote sensing technology, more and more multi-resolution, multi-temporal and multi-spectral remote

Manuscript received August 24, 2015; revised November 12, 2015. This work was supported by the Ecological Status and Ten Years Change of the Typical Area of Mineral Resources Exploitation Project under grant number STSN-10-03.

Yan Peng, Guojin He, and Zhaoming Zhang are all with the Institute of Remote Sensing and Digital Earth, Chinese Academy of Science, Beijing, China (e-mail: pengyan@radi.ac.cn, hegj@radi.ac.cn, zhangzm@radi.ac.cn). sensing image data are provided by different kinds of remote sensors, and the technology are widely applied in many fields. It also becomes an effective way to monitor the mining area.

There have been numerous researches on mine monitoring with the various satellite remote sensing data which range from middle spatial resolution images to high spatial resolution images. America conduct a program of monitoring mining area environment and disaster using remote sensing technology, which include the dynamic monitoring the coal gangue areas and reclamation areas, and it received a good effect [1]. Parls and Peterson took the open cast coal mine in the middle of Pennsylvania as a study area, and compared the vegetation and reclamation area border extraction with maximum likelihood method from SPOT, Landsat MSS, Landsat TM datasets, and the result shows that the extraction result of high spatial resolution remote sensing image is the best [2]. Niu et al. use SPOT, Landsat TM and aerial images for Jiangou mountain of Ningxia, Haibowang mining area of Neimenggu and Datong mining area of Shanxi respectively to determine the position and exploitation scale, and point out that using remote sensing and spatial technique can monitor the status of small coal mine well [3]. Mengenli et al choose Landsat TM images to monitor and assess the environment of Eynez open cast coal mine using maximum likelihood method, and the study indicates that the remote sensing technology play a major role in mining environmental assessment and monitoring [4]. These studies have shown that the remote sensing image with middle spatial resolution can monitor and qualitatively analyze the mining status of large exploitation scale well, and receive a good result. While it is difficult to monitor the regional mining area. Du proposed that applying the remote sensing image with high spatial resolution in the mine environment has a wide prospect, and it would provide technique support for resolving the problems which the traditional remote sensing technology faced [5]. Ming took Xiaoshanba monohydrallite of centrel Guizhou as study area, use QUICKBIRD remote sensing image to extract the stope, tailings pond and waste dump field [6]. Peng choose rare earth mine of Dingnan as a study case, and use ALOS image to extract two different kinds of exploitation technique mining areas which are in-situ leaping method and non in-situ leaping method including pond leaching and heap leaching way respectively, and quantitatively analyze the exploitation status, it pointed that the remote sensing image with $2.5 \mathrm{~m}$ resolution can identify clearly the ion-absorbed rare earth mine [7]. Dai implement the monitoring of illegal mining area of rare earth mine, extraction of desertification and polluted water using QUICKBIRD imageries in Xunwu [8]. The study suggests that the image with high resolution provides a good 
technological support for rapidly and accurately exploitation information extraction of ion-absorbed REM.

This research aims at investigating the exploitation status of Lingbei REM, Zudong REM and Longshe REM respectively and analyzing the reclamation effect of abandoned REM using remote sensing technique from 2000, 2005 to 2010. Therefore, an object-oriented classification approach was applied to extract REM exploitation of 2010. In order to derive the exploitation information of another years and change information rapidly and accurately, backtracking method was combined with object-oriented classification. And tasseled cap transformation was applied to analyze the reclaimed vegetation condition of abandoned REM using Landsat series data. The study will provide a technical support and decision-making for the relevant department to make plans for ion-absorbed rare earth mineral resource exploitation and to improve the environment of REM area.

\section{Study AREA AND DATASETS}

\section{A. Study Area}

The south of Jiangxi province is rich in mineral resource, especially ion-absorbed REM. Hills and mountainous regions compose the main of the south of Jiangxi which belongs to basin terrain. Three kinds of the south ion-absorbed rare earth mine (REM) which are Lingbei REM region, Zudong REM region and Longshe REM region respectively were chosen as study areas in the south of Jiangxi for studying (Fig. 1). Lingbei REM lies in the north of Dingnan county, is away $60 \mathrm{~km}$ from the county. It belongs light REE patterns of low yttrium middle europium with less than $20 \%$ Y2O3 partition function. Its exploitation history is more than 20 years, its beneficiation technology is a leaching process using ammonium sulfate. Before 2001, pond leaching method was the main exploitation technology; while heap leaching method was applied in most parts, in-situ leaching way was used in the few areas after 2002. Zudong REM locates in $10 \mathrm{~km}$ away from the east-north of Longnan county. It is a REM of high yttrium which is a type of heavy REE with over 55\% Y2O3. It has been mining up to about 30 years, and its beneficiation technology mainly used in-situ leaching method. Longshe REM locates in the east-north of Xinfeng county, $8 \mathrm{~km}$ away from the county. It belongs to middle heavy REE of middle yttrium and rich europium with about 20\% Y2O3 partition function. This kind of mineral most widely distribute in the south of china for ion-absorbed REM. It mined only several years, and was force to be closure after 2003 because of REM resources management and environment protection.

\section{B. Datasets}

In order to invest accurately the exploitation of Ion-absorbed REM, remote sensing images with high spatial resolution should be considered. ALOS, SPOT1/2/5 remote sensing images (see Table I) were finally chosen in this study, synthesizing the research purpose, cost and the need for information. And then Landsat 5/7 images were also adopted to analyze the claimed vegetation condition of abandon REM (see Table I). These datasets were all acquired at October or November considering the quality of images, the convenience for dynamic monitoring of 2000, 2005 and 2010 .

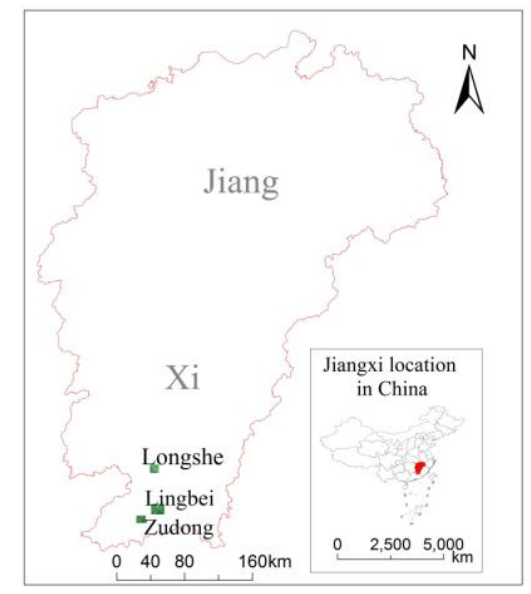

Fig. 1. Location of study area

\begin{tabular}{llll}
\multicolumn{4}{c}{ TABLE I: THE LIST OF THE OBTAINED REMOTE SENSING DATA } \\
\hline \hline ID & Satellite-sensor & Path/Row & Acquired data \\
\hline 1 & ALOS-AVNIR2 & $109 / 3090$ & $2010-11-1$ \\
2 & ALOS-PRISM & $109 / 3090$ & $2010-11-1$ \\
3 & ALOS-AVNIR2 & $109 / 3100$ & $2010-11-1$ \\
4 & ALOS-PRISM & $109 / 3100$ & $2010-11-1$ \\
5 & ALOS-PRISM & $109 / 3105$ & $2010-11-1$ \\
6 & SPOT5-HRG1J & $286 / 299$ & $2005-10-20$ \\
7 & SPOT5-HRG1J & $286 / 300$ & $2005-10-20$ \\
8 & SPOT2-HRV2PAN & $287 / 299$ & $2001-11-11$ \\
9 & SPOT2-HRV2PAN & $286 / 300$ & $2001-11-11$ \\
10 & Landsat7-ETM+ & $121 / 042$ & $2001-10-20$ \\
11 & Landsat5-TM & $121 / 042$ & $2005-10-31$ \\
12 & Landsat5-TM & $121 / 042$ & $2009-10-10$ \\
\hline \hline
\end{tabular}

\section{Methodology}

\section{A. Data Processing}

For these high resolution images, ortho-rectification, data fusion and image cut were carried out. The ALOS data was orthorectified by Rational Function Model with RPC, and the SPOT data was ortho-rectified based on physical imaging model. The errors of the ortho-rectified images are controled within 10 meters. The fused images were obtained using PANSHARP transform. In order to analyze imagery from different years and sensor, the data must be spatially co-registered so that satellite data are in the same spatial reference frame. In this process ALOS images are chosen as reference image and SPOT images are registered based on the ALOS images.

\section{B. Image Classification}

The land use of the study areas are classified as forest, bareland, water, farmland, building and Ion-absorbed rare earth mining land. For high spatial resolution image, the traditional classification method based on pixel does not apply well due to the enlargement of the internal spectral difference in the object. Therefore, the object-oriented classification way was introduced in this paper. The process of the way is that the image is segmented firstly according to 
the spectral information and shape information, and then these objects with the same spectral characteristic are merged in to a land use classification. The method can fully dig the spectral information, spatial characteristics and context information so that it can make the classification result fit better with the actual situation without increasing auxiliary information. For different periods, if each period image were carried out separately classification, amount of false changes will arise when detecting the land use change. So the backtracking method was introduced to obtain the change information and finally generate classification of study area for other periods. It can not only induced false changes efficiently, improve the accuracy, but also detect object changes for different years rapidly.

\section{1) Interpretation indexes of Ion-absorbed REM area}

In general, the beneficiation technologies of Ion-absorbed REM are divided as pond leaching method, heap leaching method and in-situ leaching method three periods. These three technologies have different characters in remote sensing images [6]. The essence of Pond leaching method and heap leaching method is similar to "moving mountain spots", they have great damage to the surface and landscape, thus the mining areas present as large areas of bare soil (see Fig. $2 \mathrm{a}$ and $2 \mathrm{~b}$ ). While In-situ leaching method directly digs well for injecting ammonium sulfate in the mountaintop or hillside, this way has less damage to the natural hill and vegetation. So the mining areas present as dense bright-dark belts along the hillside. All of the three have higher-place ponds and settling ponds as rectangles and circles (red box illustrated in Fig. 2), and ion-absorbed REM generally locates in mountains surrounding by forest, it is easily separated.

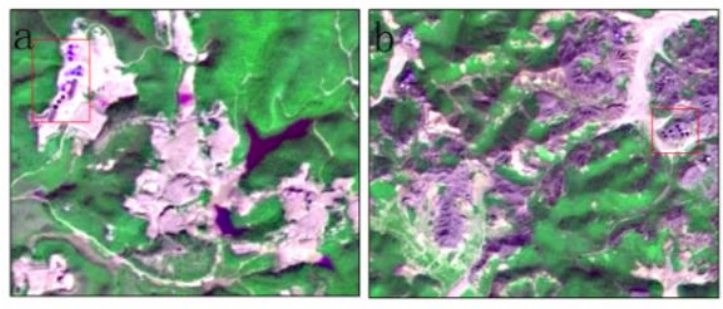

Fig. 2. ALOS images of ion-absorbed REM areas. a presents pond leaching or heap leaching method, b presents in-situ leaching method.

\section{2) Object-oriented image classification combining with backtracking}

Object-oriented classification method combining with backtracking is a process that a target object of one period is abstracted using object-oriented method firstly, secondly the abstraction result is used as a reference and border limitation for other periods object abstraction, finally other periods' object will be generated rapidly and accurately. And the classification flow is shown as Fig. 3.

As an example, the REM exploitation areas extraction of 2000, 2010 is described in detail. The ALOS image can identify the ground targets clearly with $2.5 \mathrm{~m}$ resolution, so the 2010 classification result (see Fig. 4c, Fig. 5c and Fig. 6c) was obtained firstly using object-oriented with texture feature, spectral characteristic, DEM information and shape information for ALOS image. REM exploitation area of 2000 can be generated by backtracking method. In this process, the image segmentation of 2000 is a key step. A principle should be abided, that is whatever the segmentation scale size is, multiple segmented objects of 2000 should fit well with the ground target border of 2010. Following the segmentation principle can make contribution to the following information abstraction and finally reduced false changes in a certain degree, improve the accuracy of information abstraction. Next, an REM exploitation information extraction strategy should be build up after the segmentation determined. The land use types destroyed by new mining areas are mainly forest, few areas are farmland. So the land use types of 2000 are only REM exploitation areas, forest and a small number of farmland based on REM exploitation area of 2010 as a limitation. It is easy to derive forest and farmland in the limitation areas. On the other hand, the abandoned REM areas are usually reclaimed as farmland mainly and a small part of forest. So it is also easy to extract REM exploitation areas of 2000 from the farmland or forest areas based on farmland or forest of 2010 as a limitation. Then the changes information of REM area from 2000-2010 (see Fig. 7) and REM exploitation information of 2000 can be easily and rapidly generated according the information extraction strategy. And another land use types can also be got with the described method. Finally, the land use classification results of 2000 and 2005 are generated (see Fig. 4a and 4b, Fig. 5a and $5 \mathrm{~b}$, Fig. $6 \mathrm{a}$ and $6 \mathrm{~b}$.).

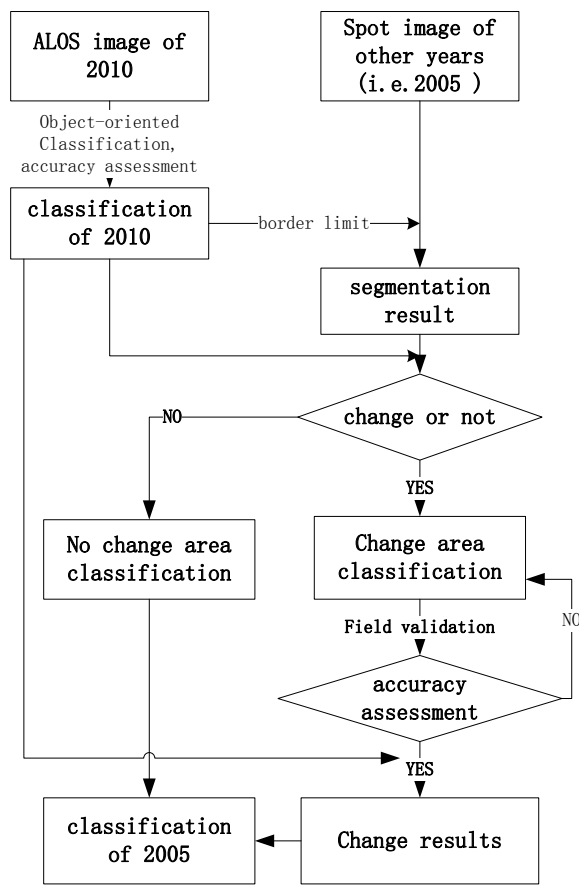

Fig. 3. Classification flow for different period.

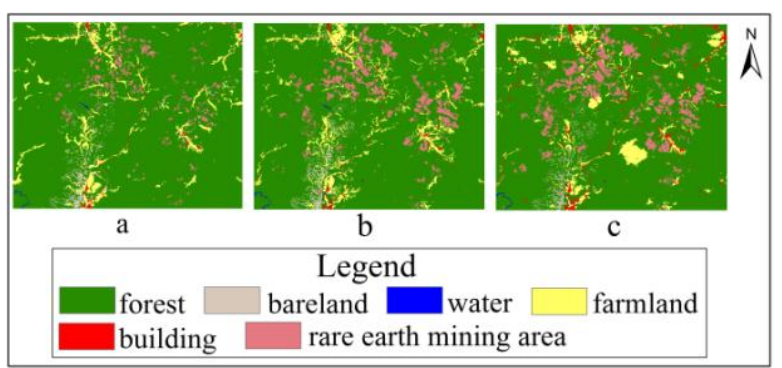

Fig. 4. Class results of Lingbei REM. a presents 2000, b presents 2005 and c presents 2010 


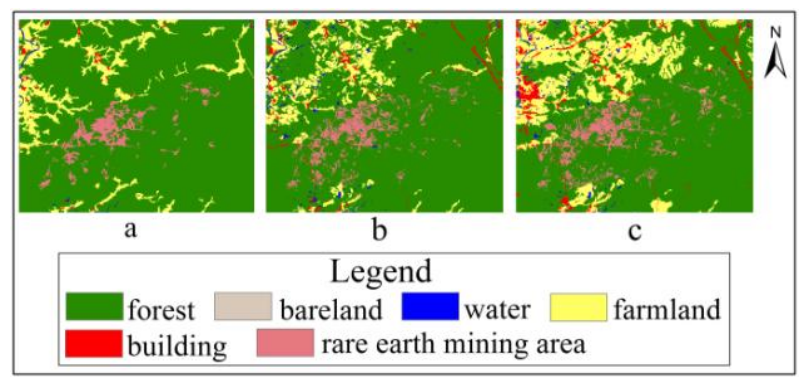

Fig. 5. Class results of Zudong REM. a presents 2000, b presents 2005 and c presents 2010.

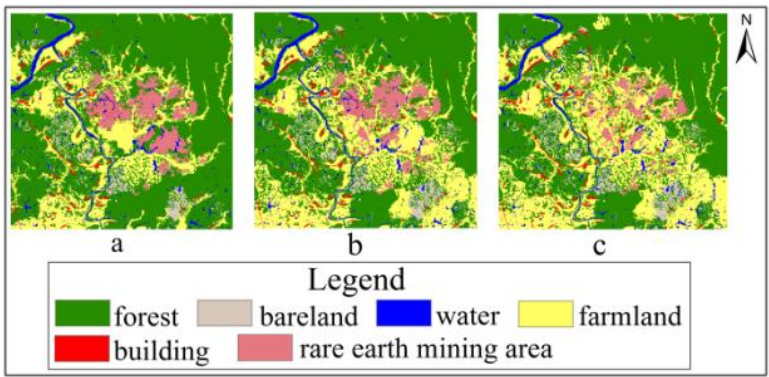

Fig. 6. Class results of Longshe REM. a presents 2000, b presents 2005 and c presents 2010 .

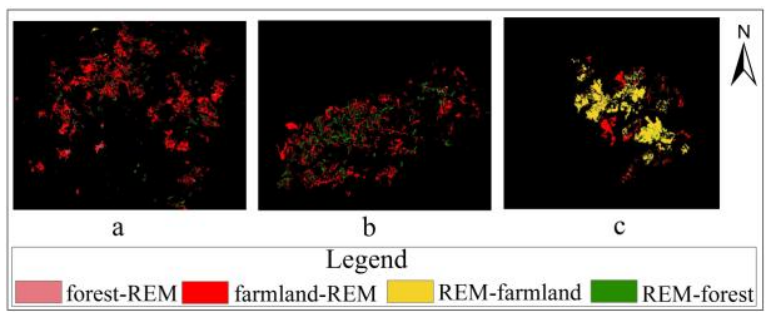

Fig. 7. Rare earth mining area changes of study area from 2000 to 2010. a presents Lingbei, $\mathrm{b}$ presents Zudong and c presents Longshe.

\section{3) Accuracy assessment}

Accuracy assessment is an important step for image classification. In order to validate the reliability of the classification results, field confirmation way combining with QUICKBIRD images as reference images was applied. Fifty points per class were randomly assigned. Some points which can't be field confirmation because of geographic restrictions were compared with QUICKBIRD images. Only classification results of 2010 were assessed, this is because results of 2000, 2005 were generated by backtracking method based on 2010 class results. So the accuracy assessment for 2010 can estimate the reliability of 2000 and 2005. The overall accuracy and Kappa coefficient for Lingbei REM area were found to be $93.33 \%$ and 0.9033 respectively (Table II), for Zudong REM area were $91 \%$ and 0.9137 respectively (Table III), and for Longshe REM area were $95.67 \%$ and 0.9539 respectively (Table IV).

\section{Tasseled Cap Transformation}

The tasseled cap transformation was applied to analyze the development of vegetation for the reclaimed area. Tasseled cap transformation was originally defined by Kauth and Thomas based on a spectral analysis of the growth of wheat in fields [9]. It is performed by taking "linear combinations" of the original image bands-similar in concept to principal components analysis in order to reduce spectral data into a few bands associated with physical scene characteristics. The first tasseled cap band corresponds to the overall brightness of the image. The second tasseled cap band corresponds to "greenness" and is typically used as an index of photosynthetically-active vegetation. The third tasseled cap band is often interpreted as an index of "wetness" (e.g., soil or surface moisture) or "yellowness" (e.g., amount of dead/dried vegetaion). Generally, the first three tasseled cap bands contain most useful information and the rest are not used. Therefore, Landsat TM images and Landsat ETM+ images were decomposed by using the tasseled cap to analyze Longshe reclaimed area (Fig. 8).
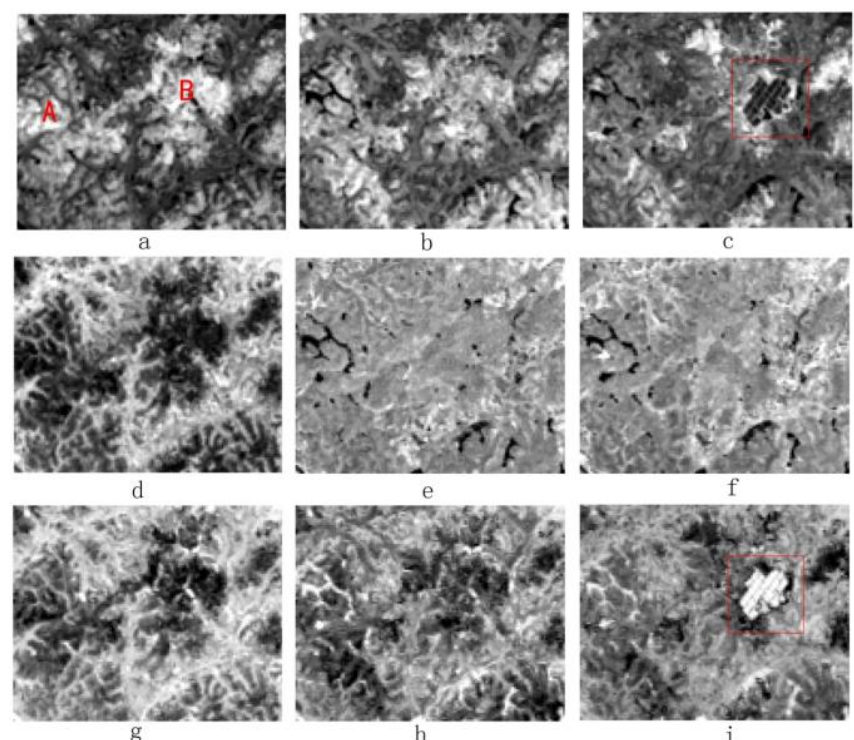

Fig. 8. Brightness, greenness and wetness images of Longshe reclaimed area. a, b, c represent brightness of 2000, 2005 and 2010 respectively; d, e, f represent greenness of 2000, 2005 and 2010 respectively; and g, h, i represent wetness of 2000, 2005 and 2010 respectively.

TABLE II: CONFUSION MATRIX FOR LINGBEI REM AREA IN 2010

\begin{tabular}{llllllll} 
Type & 1 & 2 & 3 & 4 & 5 & 6 & $\begin{array}{c}\text { User ‘s } \\
\text { accuracy }\end{array}$ \\
\hline 1-REM & 48 & 0 & 1 & 0 & 0 & 1 & $96 \%$ \\
2-Building & 0 & 45 & 2 & 0 & 1 & 2 & $90 \%$ \\
3-Farmland & 0 & 0 & 46 & 0 & 4 & 0 & $92 \%$ \\
4-Bareland & 0 & 0 & 2 & 47 & 0 & 1 & $94 \%$ \\
5-Forest & 0 & 0 & 3 & 2 & 45 & 0 & $90 \%$ \\
6-Water & 0 & 0 & 0 & 0 & 1 & 49 & $98 \%$ \\
Overall & $93.33 \%$ & & & & & \\
accuracy & & & & & & & \\
\hline \hline
\end{tabular}

TABLE III: CONFUSION MATRIX FOR ZUDONG REM AREA IN 2010

\begin{tabular}{lccccccc}
\hline \hline Type & 1 & 2 & 3 & 4 & 5 & 6 & $\begin{array}{c}\text { User 's } \\
\text { accuracy }\end{array}$ \\
\hline 1-REM & 47 & 0 & 0 & 0 & 0 & 3 & $94 \%$ \\
2-Building & 0 & 44 & 2 & 1 & 2 & 1 & $88 \%$ \\
3-Farmland & 0 & 0 & 46 & 0 & 4 & 0 & $92 \%$ \\
4-Bareland & 1 & 2 & 3 & 44 & 0 & 0 & $88 \%$ \\
5-Forest & 0 & 0 & 0 & 0 & 49 & 1 & $98 \%$ \\
6-Water & 0 & 2 & 4 & 0 & 1 & 43 & $86 \%$ \\
Overall & $91 \%$ & & & & & & \\
accuracy & & & & & & &
\end{tabular}


TABLE IV: CONFUSION MATRIX FOR LONGSHE REM AREA IN 2010

\begin{tabular}{lccccccc}
\hline \hline Type & 1 & 2 & 3 & 4 & 5 & 6 & $\begin{array}{c}\text { User's } \\
\text { accuracy }\end{array}$ \\
\hline 1-REM & 49 & 0 & 1 & 0 & 0 & 0 & $98 \%$ \\
2-Building & 0 & 48 & 1 & 0 & 1 & 0 & $96 \%$ \\
3-Farmland & 0 & 0 & 46 & 3 & 1 & 0 & $92 \%$ \\
4-Bareland & 0 & 2 & 1 & 47 & 0 & 0 & $94 \%$ \\
5-Forest & 0 & 0 & 1 & 0 & 49 & 0 & $98 \%$ \\
6-Water & 0 & 1 & 0 & 0 & 1 & 48 & $96 \%$ \\
Overall & & & & $95.67 \%$ & & \\
accuracy & & & & & & & \\
\hline \hline
\end{tabular}

TABLE V: MEAN OF TASSELED CAP BANDS FOR 2000,2005 AND 2010

\begin{tabular}{llll}
\hline \hline Year & Brightness & Greenness & Wetness \\
\hline 2000 & 0.3933 & 0.0133 & -0.2442 \\
2005 & 0.4085 & 0.1252 & -0.1231 \\
2010 & 0.4024 & 0.1493 & -0.1108 \\
\hline \hline
\end{tabular}

\section{ANALYSIS AND DisCUSS}

\section{A. Mining Situation and Analysis}

The three south ion-absorbed REM areas were scattered in study areas, especially Lingbei REM area. The mining status were evaluated quantitatively by areas statistics plots (Fig. 9) and area change maps from 2000 to 2010 (Fig. 7). Lingbei REM exploitation areas were $4.89 \mathrm{~km}^{2}, 10.47 \mathrm{~km}^{2}$ and 13.17 $\mathrm{km}^{2}$ respectively in 2000, 2005 and 2010, and it increased about $8.28 \mathrm{~km}^{2}$. Zudong REM exploitation areas were 3.93 $\mathrm{km}^{2}, 5.04 \mathrm{~km}^{2}$, and $5.74 \mathrm{~km}^{2}$, and it increased about $1.81 \mathrm{~km}^{2}$. Longshe REM exploitation area was $6.93 \mathrm{~km}^{2}$ in 2000 , but $6.51 \mathrm{~km}^{2}, 3.98 \mathrm{~km}^{2}$ respectively in 2005 and 2010 , and it reduced $2.05 \mathrm{~km}^{2}$ from 2000 to 2010. Lingbei and Zudong REM exploitation areas both expanded due to forest areas reduced mainly. And Lingbei REM exploitation areas increased more rapidly than Zudong REM. The reason for this may be that Zudong REM mainly used In-situ leaching method, and Lingbei REM mainly used in-situ heap leaching method except larger exploitation intensity in Lingbei REM area than Zudong REM area. The surface destruction by in-situ leaching method is much smaller than in-situ heap leaching method and pond leaching method. While Longshe REM area decreased rapidly from 2000 to 2010, especially from 2005 to 2010 . That is because that these reduced areas were restored as farmland including navel orange, loquat garden, lobular eucalyptus, schima and so on. Longshe REM area was forced to be abandoned in 2003 due to resource management and protection.

\section{B. Reclamation Analysis}

Table V is the mean statistics of the first three tasseled cap components and it provides the overall evaluation of reclaimed area. It is obvious that the green vegetation is much higher in 2005 with 0.1252 greenness mean value than 2000, and is also higher in 2010 with 0.1493 greenness mean value than 2005. Fig. 7 shows the spatial distribution of vegetation condition of the first three tasseled cap components for 2000 , 2005 and 2010. The brightness component is highly positive relevant to bare soil, while the greenness component is highly positive correlated with vegetation [10]. It is clear that the region A and B presented in Fig. 7a are brighter in 2000 than in other two years, especially in 2010, but the region A and B in Fig. $7 \mathrm{e}$ and $7 \mathrm{f}$ are brighter than 2000. That could be included that there is bare soil in 2000, while sparse vegetation in 2005 and lush vegetation in 2010 due to the fact that the reclamation activities began after 2003 in Longshe REM mining area and reclamations have got better effects till 2010. The wetness component provides the moisture information of the wetland environment [10]. The brightest region locates in red box illustrated in Fig. $7 \mathrm{i}$ for wetness image, and the region which located in the red box is the darkest in Fig. 7c for brightness, also brighter in Fig. 7f for greenness. As expected, the moisture content might be present in the vegetated area compared to bare soil. At the same time, the mean of wetness values is lower in 2000 for the whole region. In conclusion, the reclamation of Longshe REM area obtained a good success.

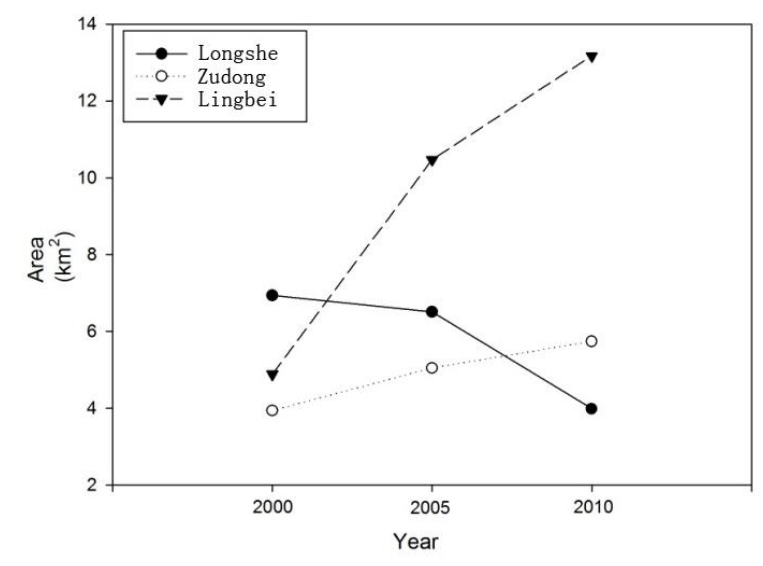

Fig. 9. Rare earth mining area statics of study area.

\section{CONCLUSIONS}

ALOS , SPOT series and Landsat series remote sensing images were used to monitor the south ion-absorbed REM area including Lingbei REM area, Zudong REM area and Longshe REM area in south of Jiangxi, China in 2000, 2005 and 2010. It is found that images with $2.5 \mathrm{~m}$ resolution are applicable to monitoring the mining status of REM area. Object-oriented class method can obtain high accuracy classification result with $90 \%$ overall accuracy in Lingbei , 90\% in Zudong, 90\% in Longshe. And the backtracking way can derive the change information quickly, reduce the false change and then improve the accuracy. It is found that the three south ion-absorbed REM areas were scattered in study areas, and the exploitation areas of Lingbei and Zudong REM tends to increase from 2000 to 2010 resulting in forest reduced mainly, while the exploitation areas of Longshe REM decreased from 2000 to 2010 owing to the fact that the mining area was forced to abandon in 2003 and began to carry out reclamation after then. In order to evaluate the vegetation condition of reclaimed area, tasseled cap transformation based on Landsat 5/7 data were applied. The analysis shows that the green vegetation increases from 2000 to 2010 due to the fact that the reclamation activities began after 2003 in Longshe REM mining area and reclamations have got better effects till 2010. It is indicated that Longshe 
abandoned REM region was successfully and sustainably reclaimed, and the success of reclamation practices could provide guidance for the management of other south ion-absorbed REM region. The analysis of classification results and tasseled cap transformation result clearly demonstrate the vital significance for monitoring the mineral resources exploitation status and the environmental impacts of mining in remote locations even in the mountainous regions using remote sensing technology.

\section{REFERENCES}

[1] L. P. Qian, "Application of remote sensing technology to the dynamic monitoring of mine environment," IEEE Trans. on Neural Networks, Safety and Environmental Engineering, vol. 15, no. 4, pp. 5-9, 2008.

[2] N. F. Parks and G. W. Peterson, "High resolution remote sensing of spatially and spectrally complex coal surface mines of central Pennsylvania: a comparison between simulated SPOT MSS and Landsat-5 thematic mapper," Photogrammetric Engineering and Remote Sensing, no. 53, pp. 415-420, 1987.

[3] B. R. Niu and S. X. Sun, "The application of SPOT satellite in coal geological survey," Coal Geology of China, vol. 11, no. 2, pp. 19-22, 1999.

[4] E. O. Mengenli, "Assessment and monitoring of environmental impacts in Eynez surface coal mine by using remote sensing," M. S. thesis, Dept. METU Mining Engineering Department, Ankara, 2001.

[5] P. J. Du, H. Zheng, and R. Hai, "Introduction to 'MINEO' project of European community and its enlightenments to monitoring and assessment of environmental impacts caused by mining in China," Journal of China Coal Society, vol. 33, no. 1, pp. 71-75, 2008.

[6] Y. Y. Min, M. Gong, and Z. Y. Lu, "Bauxite mine environment investigation based on HR satellite remote sensing data," Guizhou Geology, no. 28, pp. 154-157, 2011

[7] Y. Peng, G. J. He, and H. Cao, "Extraction of rare earth mining area using objectes-oriented classification approach based on texture characteristics," Science Technology and Engineering, vol. 13, no. 9, pp. 5590-5596, 2013.

[8] J. J. Dai and D. H. Wang, "Investigation of Ion-absorbed rare earth ore using high resolution remote sensing data," Remote Sensing Technology and Application, vol. 29, no. 6, pp. 935-942, 2008.

[9] R. J. Kauth and G. S. Thomas, "A graphic description of the spectral-temporal development of agricultural crops as seen by LANDSAT," in Proc. the Symposium on Machine Processing of Remotely Sensed Data, Purdue University of West Lafayette, Indiana, 1976, pp. 41-551.

[10] A. Erener, "Remote sensing of vegetation health for reclaimed areas of Seyitomer open cast coal mine," International Journal of Coal Geology, no. 86, pp. 20-26, 2014.

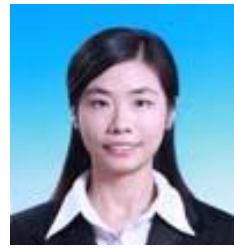

Yan Peng was born in Hunan, P.R. China, in 1988. She received the B.S. degree from University of South China, Hunan Province, China in 2010, the M.S. degree from Institute of Remote Sensing and Digital Earth, Chinese Academy of Science, Beijin, China, in 2013. And she joined the Institute of Remote Sensing and Digital Earth, CAS, as a research assistant in 2013. Her current research interests are atmospheric correction and remote sensing applications .

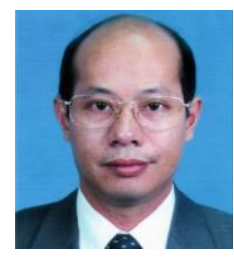

Guojin He was born in Fujian province, P. R. China, in 1968. He received the B.Sc. in geology from Fuzhou University in 1989 and the M.Sc. in remote sensing of geology from China University of Geosciences (Wuhan), in 1992. And he got the Ph.D. in geology from Institute of Geology, Chinese Academy of Sciences (CAS), in 1998. From 1992 to 2007, he worked at the Information Processing Department of China Remote Sensing Satellite Ground Station (RSGS), CAS. In 2001, he became the deputy director of Information Processing Department of RSGS, CAS. From 2004, he was a professor and director of Information Processing Department of RSGS, and also headed the research group of Remote Sensing Information Mining and Intelligent Processing. From 2008-2012, he was the professor and director of the Value-added Product Department, and the deputy director of the Spatial Data Center, Center for Earth Observation and Digital Earth, CAS. Since 2013, he has been the professor and director of the Satellite Data Based Value-added Product Department, and the deputy director of RSGS, Institute of Remote Sensing and Digital Earth, CAS. A large part of his earlier research dealt with information processing and applications of satellite remote sensing data. His current research interests are focusing on optical high resolution remote sensing image understanding as well as using information retrieved from satellite remote sensing images, in combination with other sources of data to support better understanding of the earth.

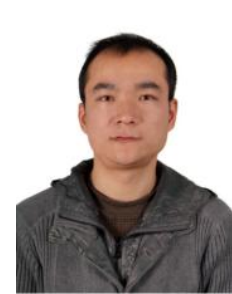

Zhaoming Zhang was born in Henan province, China, in 1980. He received his bachelor's degree in geography in Henan university in 2003; In 2006, he got his master's degree in satellite image processing in remote sensing satellite ground station, Chinese Academy of Sciences; In 2009, he received his doctor's degree in cartography and geographical information system in University of Chinese Academy of Sciences. His current research interests are land surface parameters retrieval and remote sensing applications. 